\title{
Cognitive Awareness of the EFL Learner of Contrastive Linguistics Between English and Arabic: A Case Study
}

\author{
Uzma M Hashmi \\ Vision College, Jeddah, Saudi Arabia \\ Hussam Rajab \\ English Language Institute, King Abdul-Aziz University, Jeddah, Saudi Arabia \\ Sayyed Rashid Ali Shah \\ Faculty of Languages \& Translation, King Khalid University, Jeddah, Saudi Arabia
}

\begin{abstract}
Corpus-based contrastive linguistics has rarely been thoroughly explored with regards to cognitive awareness of the English as a Foreign Language (EFL), Arabic first language (L1) speaking learners. The current study, based on an intervention, quasi-experimental quantitative research design, aims at presenting a pedagogical implementation of learners' awareness driven instructions on contrastive linguistics between English and Arabic languages interchangeably. A purposefully selected sample of 69 beginner level (A1 CEFR) Saudi EFL learners were placed into an experimental group $(n=35)$ and a control group $(n=34)$. Learners in the experimental group were exposed to four grammatical contrastive linguistics criteria (between English and Arabic) over a 14-weeks semester duration, and the control group underwent a normal taught course with no intervention over the same teaching duration. Both groups were assessed via purposefully designed, 20-items grammar test before and after the 14-weeks duration. The gathered data was analysed with one sample and independent samples t-tests. The analysis revealed the outperformance of the experimental group compared to the control group in all four grammatical contrastive linguistics criteria. The study concludes with pedagogical implications on the principle of utilising contrastive linguistics as a pedagogical tool in an EFL context.
\end{abstract}

Index Terms-Arabic L1, contrastive linguistics, EFL, error analysis, quantitative

\section{INTRODUCTION}

For any L1 speaker who is learning a new second language (L2), it is apparent that there will be some or many fundamentally structural linguistic variations between the two languages. Many researchers conduct corpus-based contrastive studies to highlight the interlinguistic differences between languages (Barlow, 2008; Curry \& Chambers, 2017; Johansson, 2008; Rabadán, Labrador, \& Ramón, 2009). Thus, a language learner aiming to acquire L2 in an accurate and effective manner, needs to be exposed to such variations in order to avoid L2 errors (Haegeman, 1985). As such, several factors may contribute to the accurate and error free Second Language Acquisition (SLA). One of such essential factors is the cognitive awareness of contrastive linguistics (sometimes referred to as differential linguistics) between the first language of the learner and the target language (L2) (Hamawand, 2020). The role which cognitive awareness plays in the process of language learning has recently gained momentum with the increasing popularity of cognitive approaches in the field of SLA (Feiz, 2016). For an L2 learner, it is imperative that any form of the L2 language should be first noticed in the input phase, and then, registered consciously in order for that L2 linguistic form to be acquired (Robinson, 1995; Schmidt, 1990). This concept is supported by many SLA researchers including Ünlü (2015) who states that: "Embracing the role that attention and awareness play in the learning process gives a greater responsibility to academicians and practitioners in terms of some intended and unintended consequences" (p. 264).

However, and despite the elaborate role and vital part which the noticing of contrastive linguistics between L1 and L2 plays, many L2 learners in different contexts struggle with certain elements of L2 they have been exposed to, and thus, still commit various lexico-grammatical, interlingual errors (Prayuda, 2020; Sahbi, Chaib, \& Khoualdi, 2019; Waelateh, Boonsuk, Ambele, \& Jeharsae, 2019; Ziad AlKadi \& Ahmed Madini, 2019). Learning an L2 can pose a challenge to EFL learners, especially those of lower proficiency levels where errors are an inevitable part of the L2 learning process (Kaweera, 2013). This is in addition to the fact that many of those errors committed are linked to negative interference and interlingual errors (Al-Khresheh, 2016; Kazazoğlu, 2020).

This paper argues that the designation of an explicit teaching scenarios of specific contrastive linguistics elements to EFL tertiary level learners, can lead to an increased level of cognitive awareness of such differences between their L1 and their target language L2. Subsequently, such awareness will diminish the possibilities of the L2 learners committing interlingual errors. 


\section{LITERATURE REVIEW}

\section{A. Contrastive Analysis Hypothesis (CAH)}

An area of applied linguistics that has witnessed ample theoretical research studies is the contrastive analysis (CA) concept which has its hypothesis, the Contrastive Analysis Hypothesis, first proposed by a pioneer in the field, Robert Lado in 1957. He emphasised that L2 learners who are exposed to a foreign language, will experience difficulties in the elements of that L2 that are different than that of their L1, whereas those features of the L2 that are similar to the learners' L1 will be easy to master and learn (Lado, 1957). Since then, CA was established as a principle in applied linguistics where different languages can be compared and most importantly contrasted for the main differences between those different languages (Nejad \& Qaracholloo, 2013). Subsequently, numerous researchers began making the connection between CA and L2 pedagogies based on differences between L1 and L2, so as to eliminate predictable errors an L2 learner might commit due to the contrasts between L1 and L2 (Chunxiang \& Baccanello, 2019; Pütz, Niemeier, \& Dirven, 2012). However, up to and until the last three decades, research studies into the pedagogical and descriptive contrastive tended to be exclusively focussed on language systems, as opposed to the much needed and effective research into the language use (Khansir \& Pakdel, 2019). As such, most of those research studies restricted themselves to the boundaries of the sentence syntax level. This is in addition to the fact that most of these studies were theoretical in principle and did not offer practical implications of contrastive nature between different languages into the L2 classroom.

\section{B. The Noticing Hypothesis}

As opposed to the natural, subconscious processes of SLA as postulated and hypothesized by Krashen (1981), a different principle of SLA hypothesized the essential role which the conscious awareness plays in language learning, has gained strength where it became an increasingly popular hypothesis based on the cognitive approaches in SLA where it was conceptualised by Schmidt (1990) and Schmidt (2012). The Noticing Hypothesis emphasises on the linguistic form which should be noticed in the L2 input and registered consciously with the L2 learners to be acquired. In other words, whenever L2 learners aim to acquire the accurate form of L2, they need to be consciously aware of the language input and attend to it to be able to cognitively process it, which ultimately lead to the input linguistic form to become an L2 intake (Ünlü, 2015). According to Schmidt (1995): "The noticing hypothesis states that what learners notice in input is what becomes intake for learning" (p. 20). As such, an L2 learner will not be able to acquire a specific L2 feature until such a feature is consciously been made aware by the learner in the process of the L2 input (Kerz, Wiechmann, \& Riedel, 2017). This is expressed by the research study conducted by Loewen and Inceoglu (2016) who emphasised the role of visual input of the Spanish language as an L2 for the learners to develop its elements of grammatical forms.

\section{Error Analysis}

The error analysis (EA) concept is considered the post CA approach where EA considers a much wider and broader concept than contrasting errors that are caused by the L1 and L2 differences. EA perceives the errors which L2 learners commit as an important insight into the L2 learners' overall learning process (Corder, 1981; Richards, 2015). Corder (1981) and Selinker, Swain, and Dumas (1975) argue that researchers must focus on the language produced (output L2 structure) by the L2 learners as they try to communicate in the target language and L2 teachers should perceive errors committed by the L2 learners as an opportunity rather than an obstacle in the overall process of SLA. Saville-Troike and Barto (2016) state that:

Error Analysis (EA) is the first approach to the study of SLA which includes an internal focus on learners' creative ability to construct language. It is based on the description and analysis of actual learner errors in L2, rather than on idealized linguistic structures attributed to native speakers of L1 and L2 (as in CA). (p. 40)

Though EA and CA overlaps in the main element of interlingual transfer between L1 and L2 with errors which L2 learners may commit, EA went beyond the boundaries of the dichotomy of positive and negative L1 to L2 transfer. This is particularly true with errors that were predicted to be inevitable with the L2 learners, however, in real life, these predicted errors did not appear in real life L2 learning situations (Allwright \& Bailey, 1991).

Notwithstanding the previous comments on the importance of CA and EA, there has been no empirical study conducted in the Saudi EFL context that presents an intervention of CA to the EFL learners in classrooms. This study aims to explore the effect of such an intervention in a tertiary level two cohorts of students at a public university in Saudi Arabia.

\section{MethodOLOGY}

The current study employed an intervention-type, quasi-experimental quantitative research design (Frey, 2018). This is due to the fact that the two intact cohorts for the two classrooms were designated as the experimental and control groups in this study and in addition, the participants were not selected randomly, rather the researchers chose other strategies (i.e., pre-test and control group) to be used so as to establish some control over extraneous variables (Ary, Jacobs, Irvine, \& Walker, 2018). 


\section{A. Participants}

As this study aimed to quantitatively accomplish the research objectives, two intact cohorts of university EFL learners enrolled on the preparatory year program (PYP). The $\mathrm{n}_{\text {total }}$ of the participants was 69 and they were on the A1 CEFR (beginner) proficiency level at a major university in KSA. All the participants were 18 years old male students. The designation of the control and experimental groups were assigned randomly and class ${ }_{1}$, the control group was $(\mathrm{n}=$ $37)$ and class $_{2}$, a control group was $(n=32)$. Both groups of students were tested for their proficiency level prior to the study and as a mandatory requirement to assign them a designated proficiency level at the start of the academic year 2019/2020. As a measure to ensure homogeneity of both, the experimental and control groups with regards to their proficiency level before the start of the research study, the Cambridge English Placement Test (CEPT) was administered to the students of both groups (Papp \& Walczak, 2016). As per the results obtained from the CEPT, the selected sample of 69 students were designated the beginner level of language proficiency (A1 on the CEFR).

The intervention protocol for the experimental group is based on the instruction strategy set forth by the Cognitive Academic Language Learning Approach (CALLA) introduced by Chamot and O'Malley (1986) where: "students are taught to use learning strategies derived from a cognitive model of learning as aids to comprehension and retention of concepts in the content area" (p.87). One of the highlights of the CALLA approach is to gradually move the language instruction from explicit to implicit teaching where the learner eventually learns how to become more autonomous and more aware of the new elements of L2 and how to best acquire them efficaciously.

As such, the intervention strategy involved the intentional introduction of CA between Arabic L1 and English L2 in four lexico-grammatical concepts which the students were previously unaware of and for these four elements, the EFL instructor designated 10 minutes of one lesson, three times a week for seven weeks module on top of the main mandatory curriculum tasks. The four lexico-grammatical concepts with marked contrasts between L1 Arabic and L2 English, were: (a) verb to be, (b) countable and uncountable nouns, (c) prepositions (in, on, at) and adjective-noun phrases.

On the other hand, the control group was taught by the same EFL instructor. However, no intervention or any mention of CA points or hints were introduced to them and the instructor delivered the main mandatory curriculum tasks to the students.

Both groups then sat a final departmental (end of semester) grammar and vocabulary (G \& V) exam which was prepared by the departmental testing unit. The final exam included several grammar-based questions which had the questions related to the contrastive points introduced to the control group during the semester and prior to the exam.

\section{B. Instruments}

\section{Cambridge English Proficiency Test (CEPT)}

The Cambridge English Proficiency Test (CEPT) was the mandated and endorsed proficiency exam aiming to provide an accurate evaluation of newly registered PYP students. CEPT provides an alignment to the CEFR where the six designated proficiency levels are: basic (A1), elementary (A2), lower intermediate (B1), upper intermediate (B2), advanced (C1) and very sophisticated (C2) levels, respectively (Docherty \& Howden, 2013). Following the CEPT at the beginning of the autumn semester of the 2019/2020 academic year, a statistical index reliability test for the CEPT was calculated and the Cronbach's coefficient alpha value was reported to be 0.992 , which considered an excellent indicator for internal consistency for the test (Tavakol \& Dennick, 2011).

Final (End of Semester) grammar and vocabulary exam

At the end of the 14 weeks semester, both the experimental and control groups sat the G \& V final exam where their scores for all the questions designated with the specific elements of the contrastive lexico-grammatical elements' scores were plotted and statistically analysed via IBM SPSS Statistics 25® software package using the statistical analysis one sample and independent samples t-tests.

\section{RESULTS}

\section{A. Pre-intervention Descriptive Statistics}

The initial set of descriptive statistical analysis tests were calculated to reveal homogeneity of both the control and experimental groups prior to the 14 weeks CA intervention. As presented in table 1, the results indicated no statistically significant differences within either group's CEPT scores or even between the groups (control and experimental).

TABLE 1

DESCRIPTIVE STATISTICS PRE-INTERVENTION

\begin{tabular}{|c|c|c|c|c|c|c|}
\hline Group & Mean & Median & $\begin{array}{c}\text { Standard } \\
\text { Deviation }\end{array}$ & $\begin{array}{c}\text { t-test significance } \\
\text { (p value) } \\
\text { (within group) }\end{array}$ & $\begin{array}{c}\text { t-test significance } \\
\text { (between groups) }\end{array}$ & $\begin{array}{c}\text { Cronbach's } \\
\text { Alpha }\end{array}$ \\
\hline Control & 37 & 38 & 3.36 & .071 & 0.0642 \\
\hline Experimental & 38 & 39 & 2.58 & .089 & 0.992 \\
\hline
\end{tabular}

As per table 1, homogeneity is established for both control and experimental groups. This is evident in the statistical analysis tests' values indicating that the $p$ values are $>0.05$ and therefore, no statistically significant differences exist 
within each group and between the two groups prior to the intervention CA approach in this study.

\section{B. Post-intervention Descriptive Statistics}

In the intervention phase of the study, the control group was given specific pedagogical instructions with regards to the four lexico-grammatical elements in the L2 English as compared and contrasted to the elements in the Arabic language. Following the intervention with the control group for the 14 weeks semester, both the control and experimental groups sat the final G \& V exam and the scores of those questions relating to the specific four lexicogrammatical elements were plotted and descriptively analysed. There was a total of 10 questions relating to the four lexico-grammatical elements where the verb to be had three questions, countable and uncountable nouns had two questions, prepositions (in, on, at) had three questions and adjective-noun phrases had two questions.

The control group as well as the experimental group had the following descriptive analysis results from the final $\mathrm{G} \&$ $\mathrm{V}$ exam where the mean, median, standard deviation was calculated for the scores of the students to the 10 items reflecting the four lexico-grammatical elements in the exam. More importantly, following a one sample t-test for each group, both the control and experimental groups had no statistically significant difference within their groups' scores. However, the two samples (independent) t-test between the scores of the control and the scores of the experimental group students revealed that there was a statistically significant difference between the scores of the control group students in the final $\mathrm{G} \& \mathrm{~V}$ exam to the scores of the experimental group students. Table 2 illustrates the statistical analysis of the two groups in the final G \& V exam.

TABLE 2

DESCRIPTIVE STATISTICAL ANALYSIS OF THE G \& V FinAL EXAM

\begin{tabular}{|c|c|c|c|c|c|c|}
\hline Group & Mean & Median & $\begin{array}{c}\text { Standard } \\
\text { Deviation }\end{array}$ & $\begin{array}{c}\text { t-test significance } \\
\text { (within group) }\end{array}$ & $\begin{array}{c}\text { t-test significance } \\
\text { (between groups) }\end{array}$ & $\begin{array}{c}\text { Cronbach's } \\
\text { Alpha }\end{array}$ \\
\hline Control & 3 & 4 & 1.52 & .412 & \multirow{2}{*}{0.000} \\
\hline Experimental & 9 & 9 & 0.99 & .631 & 0.992 \\
\hline
\end{tabular}

As illustrated in table 2, the experimental group students outperformed the control group students in the four lexicogrammatical CA elements of this study where the average mean for the experimental group was 9 compared to the control group which had the mean $=4$. In addition, the calculated independent sample t-test p-value was $<0.5$ and thus, there was a statistically significant difference between the scores of the two groups. This is an indication that the experimental group students outperformed the control group students in the final $\mathrm{G} \& \mathrm{~V}$ four lexico-grammatical elements tested in this study.

\section{DISCUSSION AND CONCLUSION}

This study aimed at highlighting the importance of cognitive awareness of tertiary level EFL students via direct and intentional intervention as part of a pedagogical approach to illuminate the students with contrastive elements that exist between English L2 and Arabic L1. The study is guided by the contrastive analysis hypothesis as well as the noticing hypothesis. Furthermore, the study adopted CALLA strategy instruction model during the intervention which was planned with the experimental group students for 14 weeks. Based on the calculated results of the descriptive statistical analysis, it can be argued that the experimental group students outperformed the control group students in the lexicogrammatical elements tested in this study. The results presented in this study are in line with other studies adopting the CA pedagogical approaches and implications (Al-Juboury, 2018; Hamdallah \& Tushyeh, 1993; Jaber, 2016; Thyab, 2016). However, the study is somehow unique in a way that the CA elements between English L2 and Arabic L1 intervention are directly introduced to the students through intervention and not many studies have adopted the same approach.

Additionally, the findings of the present study are at variance and disagreement with the assumptions of those who are proponents of Chomsky's universal grammar (Cook \& Newson, 2014) and Krashen's natural order hypothesis (Bailey, Madden, \& Krashen, 1974) and researchers who are against L2 grammar correction (Schwartz, 1993; Truscott, 1996). The outperformance of the experimental group students via direct intervention of pedagogical approach highlighting the contrasting lexico-grammatical elements between English L2 and Arabic L1 to adult EFL learners, is supported by previous research studies (e.g., Benati \& Schwieter, 2019).

It is also the conclusion the researchers of this study concur and that is, the effective awareness of lexico-grammatical contrasting elements between languages reading habits are not naturally acquired through implicit learning. Thus, EFL learners should be made aware of such contrasts between English L2 and Arabic L1 to allow them to cognitively process an accurate formulation of grammatically correct sentences in L2.

The practical implication of this study is therefore, to recommend that EFL instructors designate a short duration of lesson instructions to highlight the contrasting elements between English L2 and Arabic L1, in order to improve the L2 proficiencies of the language learners. Furthermore, the instructors should have professional development sessions to be trained on how to teach contrastive elements effectively.

\section{LIMITATIONS AND RECOMMENDATIONS FOR FUTURE RESEARCH}


This study adopted an experimental quantitative research design where an additional qualitative data would have certainly added more depth to the study and projected a much wider spectrum of varying data. Adding qualitative element will most certainly reflect on the opinions of the participants themselves and their reflection on the direct intervention of highlighting CA elements between English L2 and Arabic L2. Additionally, it would be recommended that a larger sample will make the generalizability of the findings more appealing.

\section{REFERENCES}

[1] Al-Juboury, M. T. M. (2018). Adverbs of frequency in English and Arabic as a contrastive study. Al-Bahith Journal, 20(11), 403-414.

[2] Al-Khresheh, M. H. (2016). A review study of error analysis theory. International Journal of Humanities and Social Science Research, 2, 49-59.

[3] Allwright, D., \& Bailey, K. (1991). The treatment of oral errors: what teachers do. Focus Focus on the Language Classroom: an introduction to classroom research for language teachers, 98-118.

[4] Ary, D., Jacobs, L. C., Irvine, C. K. S., \& Walker, D. (2018). Introduction to research in education: Cengage Learning. Boston: Cengage

[5] Bailey, N., Madden, C., \& Krashen, S. D. (1974). Is there a "natural sequence" in adult second language learning? Language learning, 24(2), 235-243.

[6] Barlow, M. (2008). Parallel texts and corpus-based contrastive analysis. Current trends in contrastive linguistics. Functional and cognitive perspectives, 101-121.

[7] Benati, A., \& Schwieter, J. W. (2019). Pedagogical interventions to L2 grammar instruction. In A. Benati \& J. W. Schwieter (Eds.), The Cambridge handbook of language learning (pp. 477-499). Cambridge: Cambridge University Press.

[8] Chamot, A. U., \& O'Malley, J. M. (1986). A cognitive academic language learning approach: An ESL content-based curriculum: ERIC.

[9] Chunxiang, W., \& Baccanello, J. (2019). Using contrastive terminology analysis in teaching a foreign language. Eurasian Journal of Applied Linguistics, 5(3), 461-471.

[10] Cook, V., \& Newson, M. (2014). Chomsky's universal grammar: John Wiley \& Sons. USA

[11] Corder, S. P. (1981). Error analysis and interlanguage: Oxford Univ Pr. UK

[12] Curry, N., \& Chambers, A. (2017). Questions in English and French research articles in linguistics: A corpus-based contrastive analysis. Corpus Pragmatics, 1(4), 327-350.

[13] Docherty, C., \& Howden, D. (2013). Consulting stakeholders as part of the Cambridge English: Proficiency exam revision. https://www.cambridgeenglish.org/Images/130828-research-notes-51-document.pdf\#page=20.

[14] Feiz, J. P. (2016). Metacognitive awareness and attitudes toward foreign language learning in the EFL context of Turkey. Procedia-Social and Behavioral Sciences, 232, 459-470.

[15] Frey, B. B. (2018). The SAGE encyclopedia of educational research, measurement, and evaluation: Sage Publications. Thousand Oaks, doi: http://dx.doi.org/10.4135/9781506326139.n685.

[16] Haegeman, L. (1985). Scope phenomena in English and Dutch and L2 acquisition: a case study. Interlanguage studies bulletin (Utrecht), 1(2), 118-150.

[17] Hamawand, Z. (2020). Practical applications. Modern Schools of Linguistic Thought, 75-89, Springer.

[18] Hamdallah, R., \& Tushyeh, H. (1993). A contrastive analysis of selected English and Arabic prepositions with pedagogical implications. Papers and studies in contrastive linguistics, 28(2), 181-190.

[19] Jaber, H. (2016). Contrastive syntax: Prepositions in English and in Arabic. Doctoral thesis. Beirut Arab University, Lebnon.

[20] Johansson, S. (2008). Contrastive analysis and learner language: A corpus-based approach. Compendium for the course ENG2152-Contrastive and Learner Language Analysis, University of Oslo.

[21] Kaweera, C. (2013). Writing Error: A review of interlingual and intralingual interference in EFL context. English language teaching, 6(7), 9-18.

[22] Kazazoğlu, S. (2020). The impact of L1 interference on foreign language writing: A contrastive error analysis. Dil ve Dilbilimi Çalışmaları Dergisi, 16(3), 1168-1188.

[23] Kerz, E., Wiechmann, D., \& Riedel, F. B. (2017). Implicit learning in the crowd: Investigating the role of awareness in the acquisition of L2 knowledge. Studies in Second Language Acquisition, 39(4), 711-734.

[24] Khansir, A. A., \& Pakdel, F. (2019). Contrastive analysis hypothesis and second language learning. Journal of ELT Research: The Academic Journal of Studies in English Language Teaching and Learning, 1, 35-43.

[25] Krashen, S. D. (1981). Second language acquisition and second language learning: University of Southern California.

[26] Lado, R. (1957). Linguistics across cultures: Applied linguistics for language teachers: Univ of Michigan Pr. USA

[27] Loewen, S., \& Inceoglu, S. (2016). The effectiveness of visual input enhancement on the noticing and L2 development of the Spanish past tense. Studies in Second Language Learning and Teaching, 6(1), 89-110

[28] Nejad, A. M., \& Qaracholloo, M. (2013). Frequency system of phonemes: Contrastive analysis of common standard Persian and English consonants in context-based corpora. Asian Social Science, 9(3), 76-90.

[29] Papp, S., \& Walczak, A. (2016). The development and validation of a computer-based test of English for young learners: Cambridge English young learners. In Assessing young learners of English: Global and local perspectives (pp. 139-190): Springer.

[30] Prayuda, M. S. (2020). An error analysis of Indonesian-English translation, Kairos, 4(1). 38-51

[31] Pütz, M., Niemeier, S., \& Dirven, R. (2012). Language pedagogy (Vol. 19): Walter de Gruyter. Berlin.

[32] Rabadán, R., Labrador, B., \& Ramón, N. (2009). Corpus-based contrastive analysis and translation universals: A tool for translation quality assessment English-Spanish. Babel, 55(4), 303-328.

[33] Richards, J. C. (2015). Error analysis: Perspectives on second language acquisition: Routledge. England

[34] Robinson, P. (1995). Attention, memory, and the "noticing" hypothesis. Language learning, 45(2), 283-331. 
[35] Sahbi, I., Chaib, K., \& Khoualdi, S. (2019). The impact of the explicit teaching of lexical and grammatical collocations on EFL students' writing production. MA dissertation. L'arbi Ben M'hidi University of Oum El Bouaghi, Algeria. http://bib.univoeb.dz:8080/jspui/bitstream/123456789/9032/1/version\%20de\%20la\%20biblio.pdf.

[36] Saville-Troike, M., \& Barto, K. (2016). Introducing second language acquisition: Cambridge University Press.UK

[37] Schmidt, R. (1990). The role of consciousness in second language learning1. Applied linguistics, 11(2), 129-158.

[38] Schmidt, R. (1995). Consciousness and foreign language learning: A tutorial on the role of attention and awareness in learning. Attention and awareness in foreign language learning, 9, 1-63.

[39] Schmidt, R. (2012). Attention, awareness, and individual differences in language learning. Perspectives on individual characteristics and foreign language education, 6, 27-49.

[40] Schwartz, B. D. (1993). On explicit and negative data effecting and affecting competence and linguistic behavior. Studies in Second Language Acquisition, 15(2), 147-163.

[41] Selinker, L., Swain, M., \& Dumas, G. (1975). The interlanguage hypothesis extended to children 1. Language learning, 25(1), 139-152.

[42] Tavakol, M., \& Dennick, R. (2011). Making sense of Cronbach's alpha. International journal of medical education, 2, 53-78.

[43] Thyab, R. A. (2016). Mother-Tongue interference in the acquisition of English articles by L1 Arabic students. Journal of Education and Practice, 7(3), 1-4.

[44] Truscott, J. (1996). The case against grammar correction in L2 writing classes. Language learning, 46(2), 327-369.

[45] Ünlü, A. (2015). How alert should I be to learn a language? The noticing hypothesis and its implications for language teaching. Procedia-Social and Behavioral Sciences, 199, 261-267.

[46] Waelateh, B., Boonsuk, Y., Ambele, E. A., \& Jeharsae, F. (2019). An analysis of the written errors of Thai EFL students' essay writing in English. Songklanakarin Journal of Social Sciences and Humanities, 25(3), 1-22.

[47] Ziad AlKadi, S., \& Ahmed Madini, A. (2019). EFL learners' lexico-grammatical competence in paper-based vs. computerbased in genre writing. Arab World English Journal (AWEJ) Special Issue on CALL(5), 154-175.

Uzma Hashmi is an assistant professor of linguistics at Vision College, Jeddah, Saudi Arabia. She has a PhD in Applied Linguistics and she currently teaches EFL courses at the undergraduate levels. Her research interests are Exploring EFL Teacher's Perceptions of CLIL and Its Implementation in the Saudi EFL Context as well as the latest trends in English Language Learning. ORCID: https://orcid.org/0000-0001-8355-7258

Hussam Rajab is the Research Unit Coordinator \& Representative at KAU ELI. He was awarded an MSc in Instrumentation \& Analytical Sciences from the University of Manchester Institute of Science and Technology, UK, in 1999, and a Teaching PGCE from the same university institute in 2001. He was also awarded an MA in Educational Leadership \& Management from Manchester Metropolitan University, UK, in 2008. He went on to study and research at the University of Exeter, UK, where he was awarded a $\mathrm{PhD}$ in TESOL in 2018. Dr. Rajab's research interests include contemporary research methods, SLA research, L2 reading and writing and the psychology of teaching and learning. ORCID: https://orcid.org/0000-0001-5420-1543

Sayyed Rashid Shah works as an assistant professor at the Faculty of Languages and Translation, King Khalid university, Saudi Arabia. He has doctorate in TESOL from the University of Exeter and masters in TESOL from Sheffield Hallam University, UK. He has 13 years of teaching and research experience as a TESOL professional. His research interests are teacher learning and development, educational leadership and management, educational policy, and educational philosophy and theory. ORCID https://orcid.org/0000-0003-3928-5923 